\title{
Mobilization of Sialidase from Intracellular Stores to the Surface of Human Neutrophils and Its Role in Stimulated Adhesion Responses of These Cells
}

\author{
Alan S. Cross and Daniel G. Wright \\ Departments of Bacterial Diseases and Hematology, Walter Reed Army Institute of Research, Washington, D.C. 20307-5100
}

\begin{abstract}
Desialation of cell surfaces has been associated with the initiation or modification of diverse cellular functions. In these studies we have examined the subcellular distribution of sialidase (SE) in human neutrophils as well as the mobilization of this enzyme following neutrophil activation. Separation of subcellular fractions by density gradient centrifugation showed that SE is present not only in neutrophil primary and secondary granule populations, like lysozyme, but also in plasma membrane fractions. Neutrophil activation was associated with a redistribution of SE from secondary granule-enriched fractions to the plasma membrane. Furthermore, SE activity detected on the surface of intact neutrophils with a fluorescent SE substrate increased rapidly after activation with kinetics that matched both the loss of total cell-associated sialic acid and release of free sialic acid from the cells. These activation-dependent events were in each case blocked by incubation of neutrophils with the SE inhibitor, 2-deoxy- $N$-acetyl-neuraminic acid. Aggregation responses of neutrophils as well as adhesion responses to nylon and plastic surfaces were also inhibited by 2-deoxyNANA. Our findings indicate that the activation-dependent desialation of the neutrophil surface is associated with mobilization of an endogenous SE to the plasma membrane and has a role in stimulated adhesion responses of these cells. ( $J$. Clin. Invest. 1991 .88:2067-2076.) Key words: sialic acid • neuraminidase $\bullet$ cell activation $\bullet$ granulocytes $\bullet$ aggregation
\end{abstract}

\section{Introduction}

The presence of sialic acids on cell surfaces, as terminal sugars of glycosylated cell surface molecules, has been highly conserved in evolution (1). Furthermore, there is substantial evidence that sialic acids are structural determinants for a variety of important cell-cell interactions and cellular functions, such as the adhesiveness and metastatic potential of neoplastic cells (2-4) and the phenomenon of contact inhibition in tissue culture (5).

Immature myeloid cells have been shown to be rich in cell surface sialic acid (6). Moreover, there is evidence that this high degree of sialation contributes to the negative surface charge, rigidity, and lack of adhesiveness of these cells $(7,8)$, for as myeloid precursor cells mature, they become less negatively

Address correspondence to Dr. Alan S. Cross, Department of Bacterial Diseases, Walter Reed Army Institute of Research, Washington, DC 20307-5100.

Received for publication 7 December 1989 and in revised form 6 August 1991.

The Journal of Clinical Investigation, Inc.

Volume 88, December 1991, 2067-2076 charged, more deformable and more adhesive, coincident with a progressive loss of cell surface sialic acid (6).

Cells may be desialated by sialidases (or neuraminidases) which cleave $n$-glycosidic-linked sialic acids in a one-step reaction (9). These enzymes, like sialic acids, are widely distributed in nature and exist in a variety of forms that may differ substantially in electrophysical properties and also in their ability to cleave distinct glycosidic linkages (10-12). Sialidases of mammalian cells are generally membrane bound and have been less well characterized than microbial neuraminidases (13). Nonetheless, it is evident that these enzymes may provide a mechanism for rapidly modulating cell function by modifying glycosylated cell surface structures (14).

Human neutrophils have been shown by several laboratories to contain sialidase activity $(15,16)$. Moreover, studies of the appearance of sialidase activity during induced maturation of the myeloid leukemia cell line, HL60, have suggested that neutrophil sialidase is acquired during the latter phases of neutrophilic maturation (15). Because desialation of cells has been associated with changes in various cell functions that are known to occur with neutrophil activation (e.g., increased adhesiveness [17] and decreased surface charge $[18,19])$, we were attracted to the possibility that mobilization of an endogenous sialidase in neutrophils might have a role in the functional activation of these cells. To explore this possibility, we examined the intracellular compartmentalization of sialidase in human neutrophils, together with the mobilization and redistribution of this enzyme during cell activation.

\section{Methods}

Isolation of human blood neutrophils and preparation of subcellular fractions. Neutrophils were isolated from 50-200-ml samples of heparinized venous blood obtained from healthy volunteers by combining Hypaque-Ficoll density gradient centrifugation and dextran sedimentation procedures, followed by hypotonic lysis of residual erythrocytes, as described previously $(20,21)$. For certain studies that required large numbers of cells, up to $5 \times 10^{9}$ neutrophils were isolated by the same methods from 200 to 400 -ml leukocyte concentrates obtained by continuous flow, centrifugation leukapharesis of normal volunteers (2997 continuous flow centrifuge; IBM Corp., Danbury, CT). In both cases, final leukocyte preparations contained $>95 \%$ neutrophils and were $>99 \%$ viable as determined by trypan blue dye exclusion.

For preparation of subcellular fractions, neutrophils were suspended in calcium-free $10 \mathrm{mM}$ piperazine- $N, N^{\prime}$-bis(2-ethane sulfonic acid (Pipes) buffer with $1.0 \mathrm{mM}$ ATP and $3.5 \mathrm{mM} \mathrm{MgCl} 2$ at a cell concentration of $5 \times 10^{7}$ neutrophils $/ \mathrm{ml}$. Cells were then disrupted by nitrogen cavitation at $4^{\circ} \mathrm{C}$ using a precooled pressure homogenizer (Parr Instrument Co., Moline, IL) as described previously (21). Cavitates were then centrifuged at $1,400 \mathrm{~g}$ for $10 \mathrm{~min}$ to remove nuclei and unbroken cells, and supernatants were applied to continuous sucrose gradients $(21,22)$ or to discontinuous Percoll ${ }^{\mathbb{R}}$ (Pharmacia, Uppsala, Sweden) gradients $(21,23)$ and centrifuged in a refrigerated $\left(4^{\circ} \mathrm{C}\right)$ ultracentrifuge at $95,000 \mathrm{~g}$ for $4 \mathrm{~h}$ or at $48,000 \mathrm{~g}$ for $30 \mathrm{~min}$, respectively. Stepwise elution of gradients from the bottom of centrifuge tubes was 
then carried out. Granule-rich and plasma membrane vesicle-rich fractions were identified by direct turbidometric measurements of fractions at $450 \mathrm{~nm}(21,22)$ and by the measurement of previously characterized granule and plasma membrane markers: lysozyme (24), myeloperoxidase (25), vitamin $B_{12}$ binding protein (26), and alkaline phosphatase (27), after the addition of $0.1 \%$ Triton X-100 (vol/vol, final concentration) to fractions. For certain studies that addressed the subcellular distribution of neutrophil sialidase with and without prior activation of the cells, fractions separated on discontinuous Percoll ${ }^{\mathbf{R}}$ gradients were collected by aspiration of the gradients from the top using a fine-tipped Pasteur pipette; aspirated fractions that were collected at the separate visible interfaces of gradients, where plasma membrane vesicles, secondary granules, or primary granules were concentrated, were saved as pooled fractions enriched in these distinct subcellular components.

Cellular extracts of intact neutrophils $\left(1-5 \times 10^{7}\right.$ cells $\left./ \mathrm{ml}\right)$, suspended either in HBSS, pH 7.3, or in $0.34 \mathrm{M}$ sucrose, were also prepared by sonication or rapid freeze-thawing in the presence of $0.1 \%$ Triton X-100 and protease inhibitors (aprotinin $100 \mu \mathrm{g} / \mathrm{ml}$, leupeptin $100 \mu \mathrm{g} / \mathrm{ml}$, and PMSF $1.0 \mathrm{mM}$, all obtained from Sigma Chemical Co., St. Louis, MO), followed by centrifugation at $12,000 \mathrm{~g}$ for $2 \mathrm{~min}$.

For certain studies, neutrophil extraction or subcellular fractionation was carried out after first incubating the neutrophils (suspended at a concentration of $10^{7}$ cells $/ \mathrm{ml}$ in HBSS) in a shaking water bath at $37^{\circ} \mathrm{C}$ for $5 \mathrm{~min}$ with or without $5 \mu \mathrm{g} / \mathrm{ml}$ cytochalasin B (Sigma Chemical Co.) and then for $0.5-30 \mathrm{~min}$ with or without $100 \mathrm{ng} / \mathrm{ml}$ phorbol myristate acetate (PMA), $1.0 \mu \mathrm{M}$ Met-Leu-Phe (fMLF), ${ }^{1} 1.0 \mu \mathrm{M}$ ionomycin (IMN), or $1.0 \mu \mathrm{M}$ A23187 (all obtained from Sigma). After incubation, cells were centrifuged at $250 \mathrm{~g}$ for $10 \mathrm{~min}$ in a refrigerated centrifuge, supernatants saved for subsequent assays of free sialic acid and enzymatic activities, and the pelleted cells resuspended in media appropriate for extraction or for subcellular fractionation procedures.

Measurement of neutrophil sialidase and neutrophil sialic acid content. Neutrophil sialidase activity was measured and compared with Vibrio cholerae neuraminidase (Sigma) by three separate methods: (a) by the release of free sialic acid from the artificial substrate, neuraminyllactose (Sigma, also referred to as $N$-acetylneuramin-lactose), from purified glycoproteins (e.g., transferrin, orosomucoid, fetuin [Sigma]) (13) or from intact neutrophils; (b) by release of the fluorescent moiety, 4-methylumbelliferone (4-MU) from 4-methylumbelliferyl-alpha-D$N$-acetyl-neuraminic acid (4MU-NANA) (15); and (c) by the ability of peanut lectin to agglutinate human erythrocytes pretreated with sialidase (28).

With the first method, cell extracts to be measured for sialidase activity were suspended in sodium acetate buffer $(0.8 \mathrm{M}, \mathrm{pH} 4.5)$ and added to substrates. Following incubation at $37^{\circ} \mathrm{C}$ for various periods of time, samples were centrifuged at $12,000 \mathrm{~g}$ for $2 \mathrm{~min}$ in a microfuge (Eppendorf Inc., Fremont, CA) and the supernatants assayed for free sialic acid as described below. To control for the spontaneous release of free sialic acid from substrate molecules or "substrate" neutrophils, as well as from cell extracts that served as a source of sialidase, we measured the free sialic acid released from cell extracts when mixed with buffer alone, as well as the free sialic acid released by the substrate molecules and by substrate neutrophils alone when incubated under identical conditions but without an exogenous source of sialidase. The sialic acid released under these control conditions was then subtracted from the total amount of sialic acid released by incubation of substrate molecules, or "substrate" cells, with neuraminidase or with neutrophil

1. Abbreviations used in this paper: ELAM-1, endothelial leukocyte adhesion molecule 1; fMLF, fMet-Leu-Phe; GMP-140, guanosine 5'-monophosphate; ICAM-1, intercellular adhesion molecule 1; IMN, ionomycin; KDO, 2-keto-3-deoxyoctulosonic acid; LEC-CAM, lectin cellular adhesion molecule; LFA-1, lymphocyte function-associated antigen; 4-MU, 4-methylumbellifereone; 4-MU-NANA, 4-methylumbelliferyl-alpha-D- $N$-acetyl-neuraminic acid; NA, neuraminidase; NANA, $N$-acetyl neuraminic acid; 2 deoxy-NANA, 2,3-dehydro-2deoxy- $N$-acetyl-neuraminic acid. extracts. For some studies, serine esterase inhibitors (PMSF [from Sigma], TPCK [ $N$-tosyl-L-phenylalanine chloromethyl ketone] or TLCK [ $N$-tosyl-L-lysine chloromethyl ketone], obtained from Calbiochem Corp., La Jolla, CA) were added to reaction mixtures.

To examine the possibility that neutrophils contained or generated an inhibitor of sialidase activity, we carried out mixing experiments to determine whether intact neutrophils or neutrophil extracts modified the ability of microbial neuraminidase to release sialic acid from neuraminyllactose. Release of sialic acid from neuraminyllactose mediated by neuraminidase and by neutrophils or neutrophil extracts were measured both separately and together to determine whether the sialidase activities detected individually were additive when neuraminidase and neutrophils or neutrophil extracts were mixed together. Controls included neuraminyllactose alone, neutrophil extracts alone, and cells or extracts together with neuraminidase.

Total cell-associated sialic acid (or $\mathrm{N}$-acetyl neuraminic acid [NANA]) and cell-free NANA released from sialidase substrates were measured by both the Warren thiobarbituric acid assay and by the NANA aldolase, or lyase, assay. Each assay was performed as previously described $(29,30)$. In the latter assay, samples to be measured were mixed with NANA-aldolase (Sigma) which specifically cleaves sialic acid into pyruvate and acylmannosamine; pyruvate, in the presence of lactic dehydrogenase, reduces NADH to NAD which was measured spectrofluorimetrically at an excitation wavelength of $320 \mathrm{~nm}$ and emission of $470 \mathrm{~nm}$. Sialic acid was then measured indirectly by the amount of pyruvate generated by the aldolase. Each sample was run with and without aldolase. Controls included a standard curve of pyruvate as positive control, a standard curve of sialic acid (Sigma), a control deficient in sample, and a tube with NADH alone. The amount of sialic acid was determined by comparing the relative differences between samples assayed with and without aldolase in relationship to a standard sialic acid curve.

Intact neutrophils to be assayed for total sialic acid content were extracted in $\mathrm{H}_{2} \mathrm{SO}_{4}(0.1 \mathrm{~N})$ at $80^{\circ} \mathrm{C}$ for $1 \mathrm{~h}$. Readjustment of $\mathrm{pH}$ was not necessary in the Warren assay; however, in the aldolase assay, the sample was titrated to $\mathrm{pH} 7.4$ with $0.1 \mathrm{~N} \mathrm{NaOH}$ before the addition of NANA aldolase.

The 4MU-NANA assay of sialidase in neutrophil extracts was performed as described previously (15). For these assays, $100 \mu \mathrm{M}$ leupeptin, $1 \mathrm{mM} \mathrm{PMSF}$, and $100 \mu \mathrm{g} / \mathrm{ml}$ aprotinin were added to cell preparations before extraction procedures. Freshly prepared 4MU-NANA was added at a final concentration of $0.5 \mathrm{mM}$ to sodium acetate buffer, $0.075 \mathrm{mM}, \mathrm{pH} 4.5$. After incubation at $37^{\circ} \mathrm{C}$ for $2 \mathrm{~h}$, the release of NANA from the substrate was determined by measurement of fluorescence at $440 \mathrm{~nm}$ after the addition of ethanol and $\mathrm{NaOH}$ to the reaction mixture (15); measurements were then correlated with a 4MU fluorescence standard.

For studies designed to detect sialidase activity on the neutrophil cell surface, intact neutrophils, after incubation in HBSS, pH 7.4, at $37^{\circ} \mathrm{C}\left(10^{7}\right.$ cells $\left./ \mathrm{ml}\right)$ for $0.5-10 \mathrm{~min}$ with or without $100 \mathrm{ng} / \mathrm{ml} \mathrm{PMA}$, $1.0 \mu \mathrm{M}$ IMN, or $1.0 \mu \mathrm{M} \mathrm{fMLF}$, were resuspended in the 4MU-NANA assay buffer at pH 7.0 and incubated for $30 \mathrm{~min}$, followed by measurement of $4 \mathrm{MU}$ fluorescence in the reaction mixture. In certain studies sialidase activity detected with intact cells incubated in buffer containing 4MU-NANA was measured in the presence of the sialidase inhibitor, 2,3-dehydro-2-deoxy- $N$-acetyl-neuraminic acid (2deoxy-NANA, Boehringer-Mannheim Corp., Indianapolis, IN) or a structurally similar compound lacking sialidase inhibitory activity, 2-keto-3-deoxyoctulosonic acid (KDO, Sigma).

For the third sialidase assay procedure, samples to be measured for sialidase activity were incubated with a suspension of human erythrocytes according to the method of Pereira (28). The ability of peanut lectin (Arachis hypogaea, Sigma) to induce agglutination of the erythrocytes following incubation was then used as a measure of desialation mediated by sialidase activity in the sample.

To determine the extent to which neutrophil sialidase remains membrane associated or is released as a soluble enzyme after disruption of cells or subcellular organelles, extracts were prepared from neu- 
trophils or subcellular fractions that were suspended in HBSS and protease inhibitors in the presence or absence of $0.1 \%$ Triton X-100 and sonicated. After centrifugation at $10,000 \mathrm{~g}$ for $10 \mathrm{~min}$ at $4^{\circ} \mathrm{C}$, supernatants were assayed for sialidase activity by incubation with the artificial substrate, neuraminyllactose, for $1 \mathrm{~h}$ at $37^{\circ} \mathrm{C}$. Release of sialic acid was then determined by the Warren assay.

Measurement of radiolabelled sialic acid binding to neutrophils. Neutrophils were prepared from human peripheral blood as described and adjusted to $8 \times 10^{7}$ in HBSS. Radiolabelled sialic acid (cytidine 5 '-monophospho $\left[{ }^{14} \mathrm{C}\right]$ sialic acid, ammonium salt, Amersham Corp., Arlington Heights, IL) was added to replicate aliquots of cells in the presence or absence of excess $(100 \mu \mathrm{g} / \mathrm{ml})$ unlabelled sialic acid. The neutrophils were retained on ice or at $37^{\circ} \mathrm{C}$ without stimulation, or were stimulated for up to $10 \mathrm{~min}$ with $1 \mu \mathrm{M} \mathrm{IMN}$ at $37^{\circ} \mathrm{C}$. Aliquots $(100 \mu l)$ were then centrifuged in triplicate through silicone oil (Versilube; General Electric Co., Waterford, NY) and cell pellets were treated overnight with tissue solubilizer (Solusol; National Diagnostics, Inc., Somerville, NJ) and counted in a scintillation counter.

Measurement of stimulated neutrophil aggregation and spontaneous adhesion of neutrophils to nylon fibers or plastic surfaces. Homotypic neutrophil aggregation was measured by a standard procedure described previously (31) using a Lumi-aggregometer (Chrono-Log Corp., Havertown, PA). Cells were incubated with and without $1.0 \mu \mathrm{M}$ $\mathrm{fMLF}, 1.0 \mu \mathrm{M}$ IMN, or $100 \mathrm{ng} / \mathrm{ml}$ PMA, and with or without freshly prepared 3-250 $\mu \mathrm{g} / \mathrm{ml} 2$-deoxyNANA or $\mathrm{KDO}$, which was added to stirred neutrophil suspensions immediately before addition of the stimuli.

Neutrophil adhesion to nylon fibers or to albumin-coated plastic tissue culture plates was measured using assay systems that had been adapted from methods described previously (31). For measurements of adhesion to nylon fibers, isolated neutrophils (see above) were resuspended at a final concentration of $5 \times 10^{6} \mathrm{cells} / \mathrm{ml}$ in heparinized autologous plasma that had been separated from venous blood samples used for neutrophil isolation and had been diluted 1:1 with HBSS. 1-ml aliquots of neutrophil suspensions, prewarmed to $37^{\circ} \mathrm{C}$, were delivered to nylon fiber-packed mini-columns, with or without $3-250 \mu \mathrm{g} / \mathrm{ml}$ 2-deoxyNANA, KDO, or NANA, and with or without $0.1 \mu \mathrm{M} \mathrm{ALF}$, which had been added to cell suspensions immediately before delivery to the mini-columns. Replicate nylon fiber mini-columns were prepared from disposable tuberculin syringes, with needles and plungers removed, by packing each with $20 \mathrm{mg}$ of sterile nylon fibers (type 200; Fenwall Laboratories, Morton Grove, IL). Each column was then suspended in a sterile polypropylene test tube to collect cells that passed through the columns. Once aliquots of neutrophil suspensions were delivered to the columns, they were placed in a humidified incubator at $37^{\circ} \mathrm{C}$ for $5 \mathrm{~min}$ after which cells that had passed through individual columns were counted. The percent of cells that had adhered to the nylon fibers and had not passed through the mini-columns was then calculated.

For measurement of neutrophil adhesion to plastic, isolated neutrophils were resuspended at a final concentration of $5 \times 10^{6} / \mathrm{ml}$ in HBSS. Replicate 1.0 -ml aliquots of cell suspensions, prewarmed to $37^{\circ} \mathrm{C}$, were delivered to flat bottom plastic culture wells (six-well plastic culture dishes; Costar Corp., Cambridge, MA) that had been previously incubated with HBSS + $2 \%$ BSA and then rinsed with HBSS and dried. Cells were incubated in the plastic wells in a humidified $37^{\circ} \mathrm{C}$ incubator for precisely $3 \mathrm{~min}$, with or without 3-250 $\mu \mathrm{g} / \mathrm{ml}$ 2-deoxyNANA, $\mathrm{KDO}$, or NANA, and with or without $0.1 \mu \mathrm{M}$ fMLF, which had been added to cell suspensions immediately before delivery to the plastic culture wells, after which nonadherent cells were aspirated from the wells and counted. The percent of cells that remained adherent to the plastic wells was then calculated.

\section{Results}

Detection and characterization of neutrophil sialidase

As reported previously by others $(15,16)$, sialidase activity could be detected readily in extracts of purified human blood neutrophils. This activity was maximal at $\mathrm{pH} 4.5-5.0$ and was, like other mammalian sialidases (32), a heat labile enzyme that was not inhibited by serine esterase inhibitors (PMSF, TPCK, or TLCK). Greater than $60 \%$ of activity was lost when neutrophil extracts were incubated $>60 \mathrm{~min}$ at $56^{\circ} \mathrm{C}$, and $>80 \%$ of activity was lost with incubations at $100^{\circ} \mathrm{C}$ for $5 \mathrm{~min}$. In addition, substantial amounts of sialidase activity were lost from cell extracts with a single cycle of freeze-thawing, which hindered the study of stored samples.

In Table I, substrate specificities of neutrophil sialidase are compared with those of $V$. cholerae neuraminidase. Both were found to be active against the artificial sialidase substrate, neuraminyllactose, and the activity recoverable from $10^{7}$ neutrophils was roughly equivalent to $20 \mu \mathrm{U}$ of neuraminidase. Sialidase in neutrophil extracts was relatively more active in mediating the release of free sialic acid from intact neutrophils and in cleavage of 4MU-NANA, but unlike neuraminidase, lacked activity against a number of other substrates.

Neutrophils did not appear to have a sialidase inhibitory activity that might account for differences in the apparent activities in neutrophil sialidase vs. microbial neuraminidase, in that the addition of intact neutrophils (resting or stimulated), or neutrophil extracts, to a mixture of $V$. cholerae neuraminidase and neuraminyllactose did not decrease the release of free sialic acid from neuraminyllactose that was mediated by neuraminidase alone (data not shown).

\section{Subcellular localization of neutrophil sialidase}

Sialidase activity was recoverable from subcellular fractions of nitrogen-cavitated, resting neutrophils separated by ultracentrifugation on both continuous sucrose gradients $(21,22)$ or on discontinuous Percoll ${ }^{R}$ gradients $(21,23)$. As is illustrated in Figs. 1 and 2, and as has been well documented previously (22, 23), both techniques permitted the separation of cell fractions enriched in plasma membrane vesicles, peroxidase-negative

Table I. Comparison of Neuraminidase and Neutrophil Sialidase Activities

\begin{tabular}{llcc}
\hline & & \multicolumn{2}{c}{ Source of sialidase activity } \\
\cline { 3 - 4 } \multicolumn{1}{c}{ Substrate $^{*}$} & Assay $^{*}$ & V. cholera NA & Neutrophils \\
\hline Neuraminyllactose & (W) & 79.30 & 1.38 \\
& (L) & 17.10 & 0.37 \\
Intact neutrophils & (W) & 3.71 & 1.31 \\
& (L) & 1.86 & 0.25 \\
Mucin & (W) & 0.63 & 0 \\
Transferrin & (W) & 0.09 & 0 \\
Fetuin & (W) & 0.60 & 0 \\
Orosomucoid & (W) & 1.29 & 0 \\
4MU-NANA & (Fl) & 0.74 & 0.13 \\
RBC/peanut agglutinin" & & $4+$ & 0 \\
& & & \\
\hline
\end{tabular}

* Neuraminyllactose, mucin, transferrin, fetuin, and orosomucoid, all at $1 \mathrm{mg} / \mathrm{ml}$. Intact neutrophils at $4 \times 10^{7} / \mathrm{ml} .{ }^{\ddagger} \mathrm{W}$, Warren assay; L, lyase assay; Fl, $4 \mathrm{MU}$ fluorescence assay. ${ }^{8} \mathrm{Data}$ expressed as micromoles of free sialic acid released $/ 1 \mathrm{mU}$ per $\mathrm{h}$ for $V$. cholera neuraminidase, and as micromoles of free sialic acid released $/ 10^{7}$ PMNs per $\mathrm{h}$ for sialidase activity derived from neutrophil extracts. "Positive agglutination of sialidase-treated red blood cells ( $2 \%$ suspension) in $0.1 \mathrm{M}$ PBS, pH 6.8 at $8 \mu \mathrm{g} / \mathrm{ml}$ lectin (see Methods, ref. 28). 

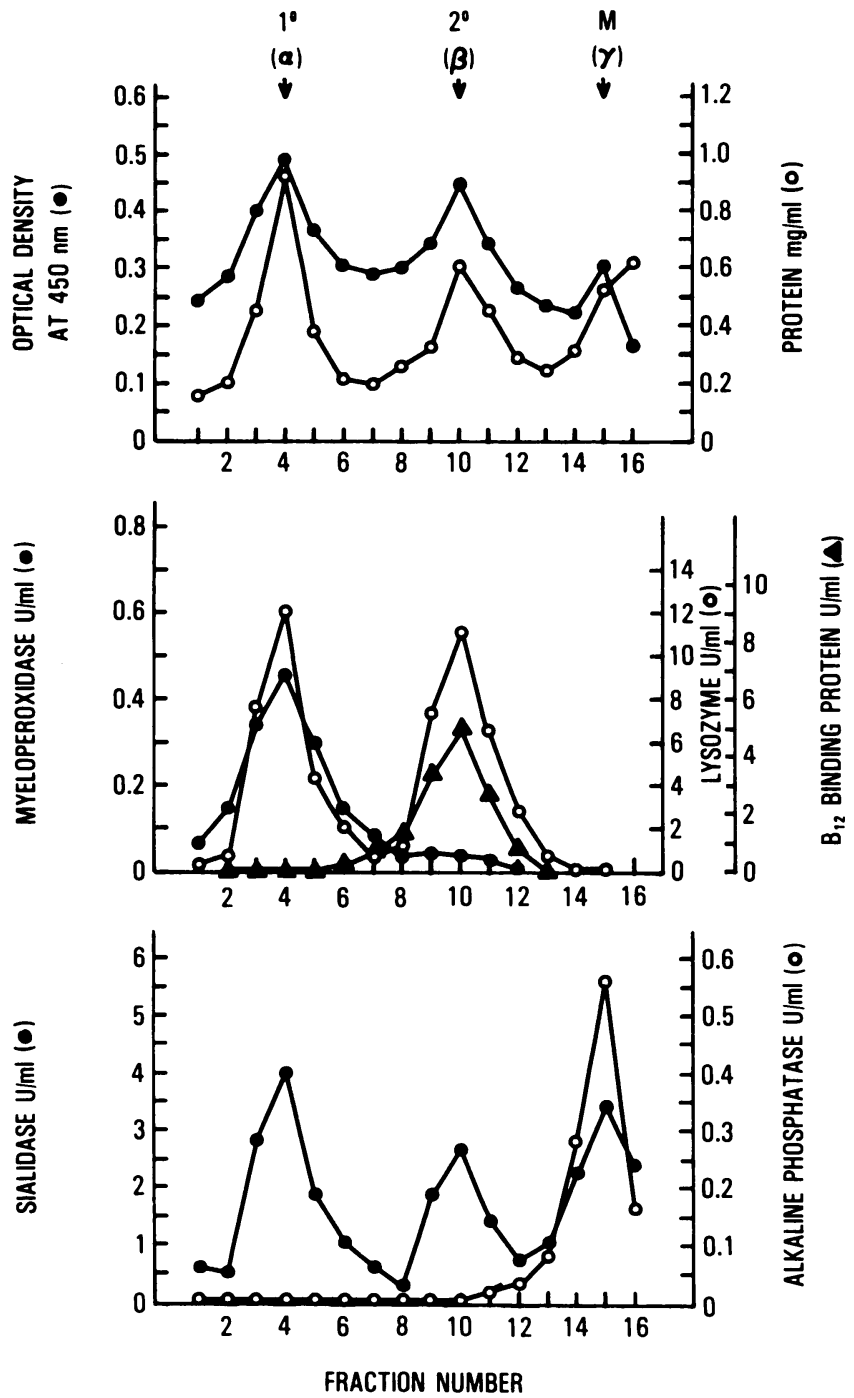

Figure 1. Separation of cell fractions by Percoll ${ }^{\mathbb{R}}$ gradient from nitrogen-cavitated, resting neutrophils. Upper panel shows separation into plasma membrane vesicles $(M)$, peroxidase-negative secondary $(\beta)$, or peroxidase-positive primary $(\alpha)$ granules by turbidity and protein measurements. Middle panel shows distribution of myeloperoxidase $(\bullet)$, lysozyme (o), and vitamin $B_{12}$-binding protein ( $\mathbf{\Delta}$ ) activities. Lower panel demonstrates localization of sialidase activity $(\bullet)$ and alkaline phosphatase (O) activities. $1 \mathrm{U}$ of sialidase activity $=1.0 \mu \mathrm{g}$ sialic acid release from neuraminyllactose/h. Results of a representative cell fractionation study are shown.

secondary granules, or peroxidase-positive primary granules. However, the sucrose gradient technique also resolved two distinct primary granule populations with different densities.

Shown in Fig. 1 are representative results of fractionation studies using the Percoll ${ }^{R}$ gradient technique, with elution of gradients from the bottom of ultracentrifuge tubes. Elution of granule or membrane-rich fractions is indicated in the top panel of the figure by turbidity and protein measurements. Shown in the middle and bottom panels of the figure are the localizations of myeloperoxidase (in the dense, primary granule-rich fractions), $\mathrm{B}_{12}$-binding activity (in the lighter density, secondary granule-rich fractions), lysozyme (in both primary and secondary granule fractions), alkaline phosphatase (in the
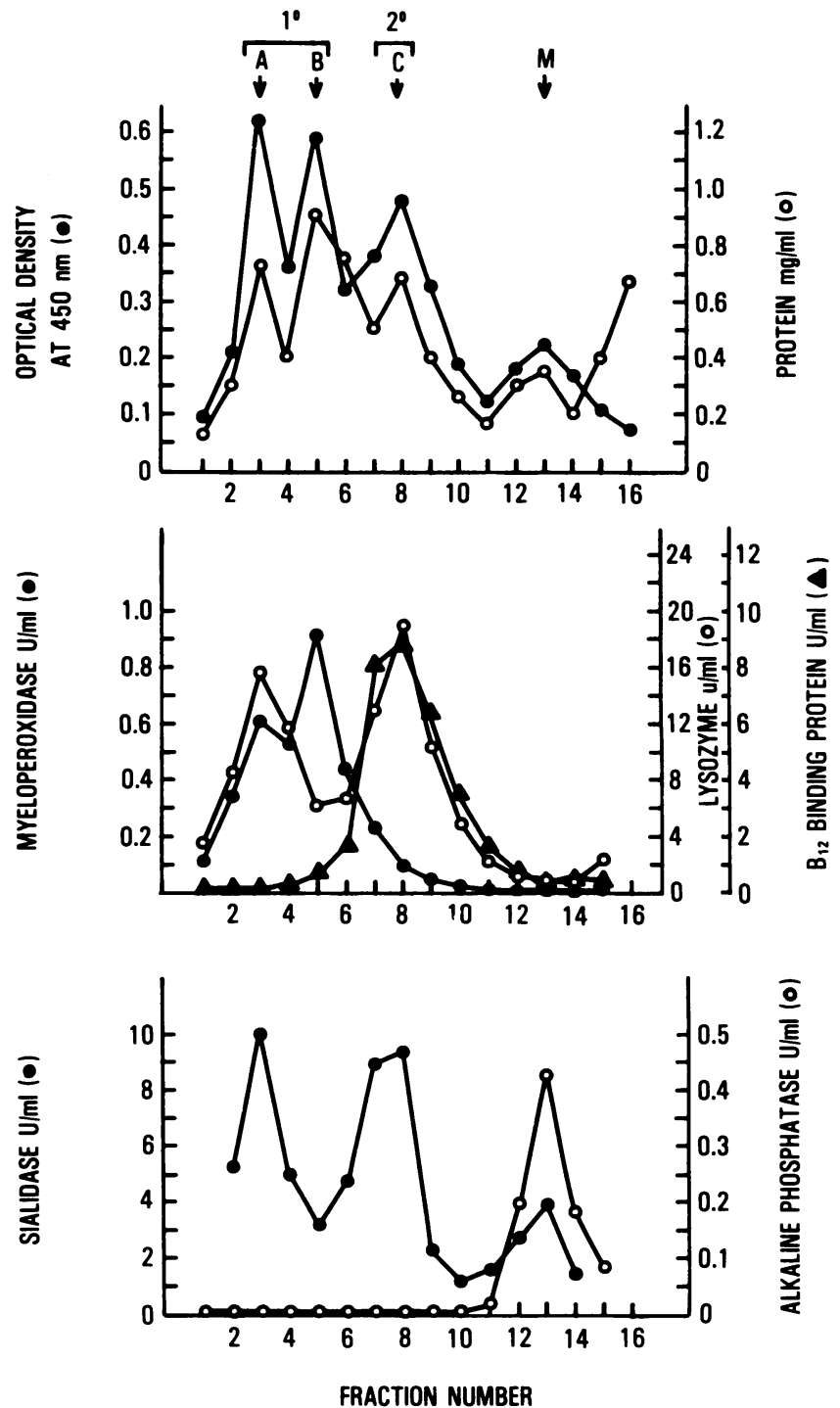

Figure 2. Separation of cell fractions by continuous sucrose gradient from nitrogen-cavitated, resting neutrophils. Upper panel shows separation into plasma membrane vesicles $(M)$, secondary granules $(C)$, and two populations $(A$ and $B$ ) of primary granules by turbidity and protein measurements. The middle panel shows the distribution of myeloperoxidase ( $\bullet$ ), lysozyme (o), and vitamin $B_{12}$-binding protein $(\triangle)$ activities. The lower panel shows the distribution of sialidase (•) and alkaline phosphatase $(0)$ activities, demonstrating that sialidase activity is recovered only from the more dense of the two peroxidase-positive primary granule population. $1 \mathrm{U}$ of sialidase activity $=1.0 \mu \mathrm{g}$ sialic acid released $/ \mathrm{h}$. Results of a representative cell fractionation study are shown.

plasma membrane vesicle-rich, light density fractions), and sialidase activity (shown in the bottom panel) which was recovered from both primary and secondary granule fractions, as well as from plasma membrane fractions.

Fig. 2, which illustrates cell fractionation using the continuous sucrose gradient technique, shows very similar results for the subcellular localization of sialidase activity. However, in these studies it was evident that sialidase, like lysozyme, is recoverable only from the more dense of the two peroxidase positive, primary granule populations, resolved by this technique. 
Translocation of sialidase activity in activated neutrophils When comparative Percoll ${ }^{\mathbf{R}}$ gradient fractionation studies were carried out with both resting and activated neutrophils, it was evident that activation of the cells by PMA, by the ionophore, A23187, or by the chemotactic peptide fMLF both with and without preincubation with cytochalasin B, were in each case associated with an apparent translocation of sialidase activity from secondary granule-rich fractions to fractions containing plasma membrane vesicles (Fig. 3). This translocation of sialidase was evident both when enzyme activities in fractions were expressed in terms of total numbers of cells fractionated (Fig. $3 \mathrm{~A}$ ) and when expressed in terms of total protein recovered in the fractions (Fig. $3 \mathrm{~B}$ ). The decline in sialidase specific activity in secondary granule fractions (Fig. $3 B$ ), in addition to the decline in total sialidase activity detected in the fractions, suggested that the sialidase translocated to the plasma membrane is derived from a subpopulation of the organelles present


Figure 3. Sialidase activity recovered from pooled primary granule, secondary granule, and plasma membrane fractions (obtained by Percoll gradient fractionation) of resting neutrophils (control) and neutrophils stimulated by PMA, $100 \mathrm{ng} / \mathrm{ml}$, the calcium ionophore A23187 $(1.0 \mu \mathrm{M})$, and fMLF $(1.0 \mu \mathrm{M})$ in the presence of cytochalasin $\mathrm{B}(5 \mu \mathrm{g} / \mathrm{ml})$. Translocation of sialidase activity from secondary granule to plasma membrane fractions is evident when sialidase is expressed in terms of total number of cells fractionated $(A)$ and in terms of total protein recovered in fractions, or specific activity $(B)$. Results represent mean values \pm SEM for three replicate studies. $\square$, Control; , PMA; $\square$, A23187; : fMLP. in the secondary granule rich fractions. It was noteworthy in this regard that translocation of sialidase present in "secondary" granule fractions to the plasma membrane fractions was found to occur with AMLF stimulation in the absence of cytochalasin, conditions with which little or no granule exocytosis was evident by release of the primary and secondary granule markers, beta-glucuronidase and $\mathrm{B}_{12}$-binding protein.

The relative distribution of sialidase activities in the primary, secondary, and plasma membrane fractions varied somewhat among separate cell preparations; the distribution of sialidase also varied depending upon whether all fractions of a density gradient were analyzed, as in Figs. 1 and 2, or whether pooled fractions were examined, Fig. 3 . The relative recovery of sialidase from the secondary granules was consistently greater than that from primary granules when pooled fractions of gradients were examined (e.g., Fig. 3). Variations in the relative recoveries of sialidase activity from secondary granule and plasma membrane fractions, on the other hand, were observed with different preparations of unstimulated neutrophils (as in the separate gradient studies shown in Fig. 1 and Fig. 2) regardless of the fractionation procedure used, and we believe that these variations are likely to have been caused by differences in the partial activation of cells that occurred during their preparation.

\section{Detection of sialidase activity on the surface of intact neutrophils}

When intact resting neutrophils were incubated with the artificial sialidase substrate 4MU-NANA under conditions in which cell viability (e.g., dye exclusion) was preserved (30-min incubations in acetate buffer containing 4MU-NANA, pH 7.0), low but detectable levels of sialidase were measured by release of the fluorescent 4MU-NANA cleavage product, 4MU. As shown in Fig. 4, this apparent cell surface sialidase activity was increased substantially when neutrophils were incubated briefly in HBSS at pH 7.4 with fMLF, the ionophore A23187, or PMA before being resuspended in acetate buffer containing 4MU-NANA. The ionophore and IMLF were found to cause relatively rapid but transient increases in this sialidase activity detected with intact cells, while PMA caused a more gradual but persistent increase in this activity. In all cases, the addition of $100 \mu \mathrm{M}$ (or $30 \mu \mathrm{g} / \mathrm{ml}$ ) 2-deoxyNANA, a specific, competitive inhibitor of sialidase (33) to both stimulated and unstimulated cells exposed to the 4MU-NANA substrate eliminated all detectable cell surface sialidase activity (data not shown).

It was anticipated that a rapid cell surface expression of sialidase, which interacts with both exogenous substrate and inhibitor following neutrophil activation, would be associated with an equally rapid expression of sialate binding. We, therefore, examined the binding of exogenous, radiolabelled sialic acid to PMNs that had been activated with the ionophore IMN. We observed a rapid, transient increase in the binding of radiolabelled sialate to neutrophils which was apparent within $1 \mathrm{~min}$ after IMN stimulation to levels $>150 \%$ of baseline and which was blocked by the addition of excess unlabelled sialic acid. Of note, the transience of this IMN-stimulated increase in sialate binding was kinetically very similar to that observed with the increase in apparent cell surface sialidase activity stimulated by the ionophore A23187 (Fig. 4) or by IMN (data not shown) under identical conditions.

There was no detectable release of soluble sialidase activity from neutrophils (e.g., enzymatic activity that remained in the 

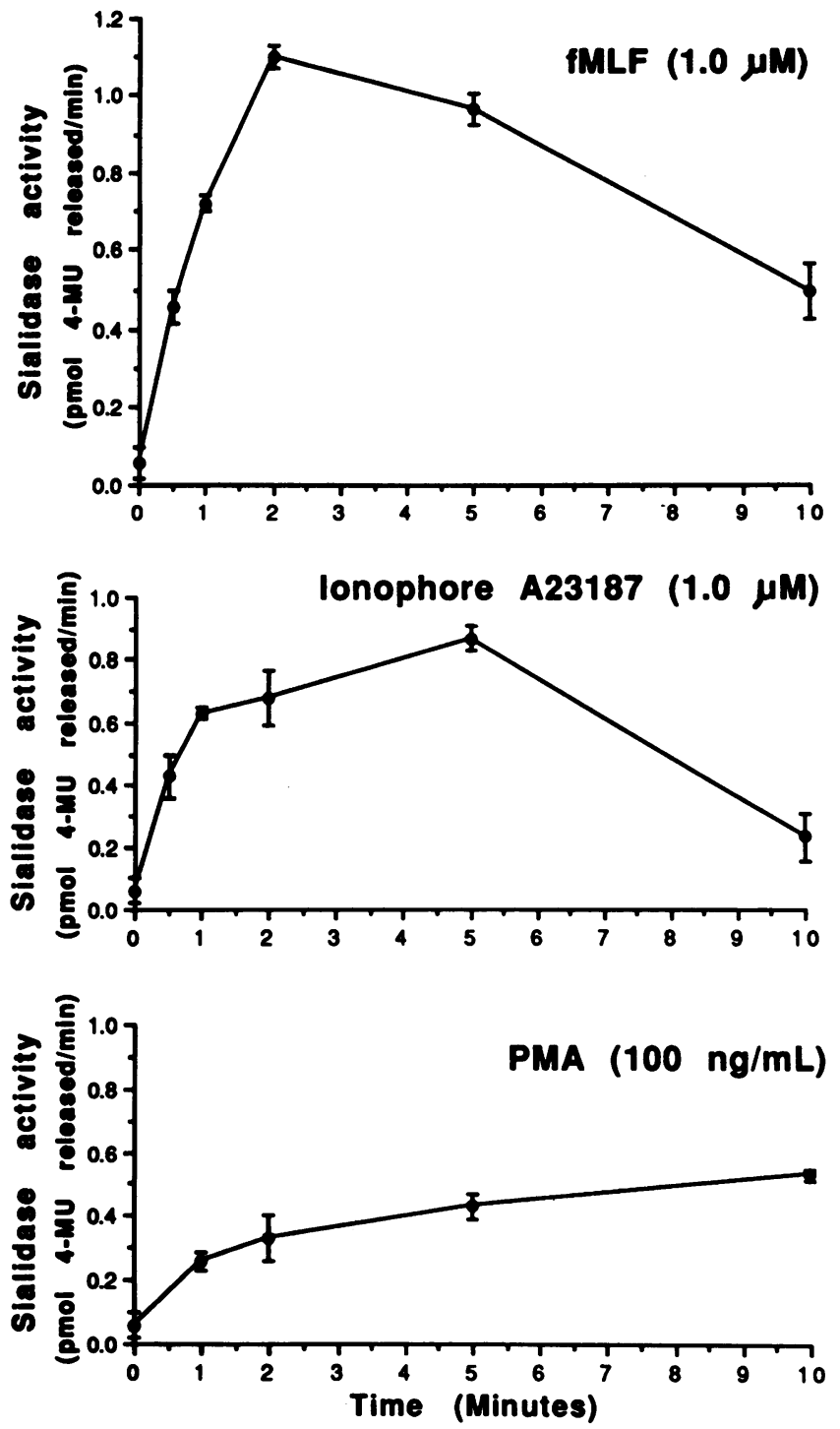

Figure 4. Sialidase activity detected with intact neutrophils incubated with the sialidase substrate 4MU-NANA. Increases in cell-associated sialidase activity were observed after stimulation of intact neutrophils with $\mathrm{MLF}(1.0 \mu \mathrm{M})$, ionomycin $(1.0 \mu \mathrm{M})$, or PMA $(100 \mathrm{ng} / \mathrm{ml})$. Results represent mean values \pm SEM for four replicate measurements.

supernatant following centrifugation of the cells at $10,000 \mathrm{~g}$ for $10 \mathrm{~min}$ ) under any of the cell activation conditions that were examined. Moreover, sonication of intact neutrophils, by itself, also failed to release soluble sialidase activity from the cells. Rather, soluble sialidase activity was detected only upon treatment of neutrophils or cell fractions with detergents (e.g., $0.1 \%$ Triton X-100 [data not shown]).

\section{Loss of sialic acid from activated neutrophils}

Activation of neutrophils by PMA, IMN, and AMLF was also found to be associated with both a release of sialic acid into the surrounding medium (Fig. $5 A$ ) and a rapid loss of cell-associated sialic acid (Fig. $5 B$ ). Furthermore, this desialation phenomenon, illustrated in Fig. 5, occurred with kinetics that were similar to those observed with increases in apparent cell surface sialidase activity (as described above) in neutrophils exposed to these different activating stimuli. As was the case with the ex-

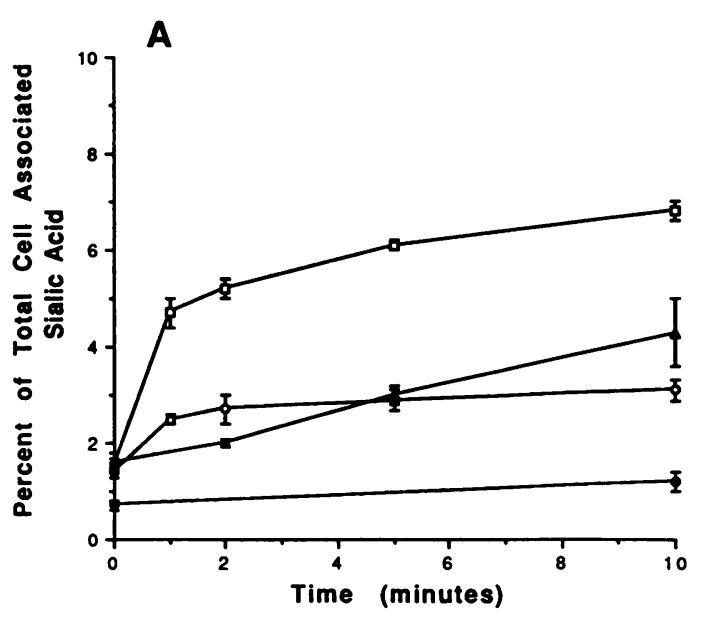

B



Figure 5. Release of free sialic acid $(A)$ and loss of cell-associated sialic acid $(B)$ after activation of neutrophils by PMA $(100 \mathrm{ng} / \mathrm{ml}, \Lambda)$; ionomycin (1.0 $\mu \mathrm{M}, \square)$; or fMLF (1.0 $\mu \mathrm{M}, \mathrm{O})$. Neutrophils were exposed to activating stimuli or to incubation buffer alone (๑) for 0-10 min, and then centrifuged, $1,000 \mathrm{~g}$ for $2 \mathrm{~min}$ at $4^{\circ} \mathrm{C}$. Sialic acid levels were then determined in the supernatants and in the cell pellets after hydrolysis in $0.1 \mathrm{~N} \mathrm{H}_{2} \mathrm{SO}_{4}$ by the thiobarbituric acid assay. Results represent mean values \pm SEM for four replicate measurements.

pression of cell surface sialidase, loss of sialic acid was more rapid and short-lived with $\mathrm{AMLF}$ and ionophore activation than with PMA. It should be noted that not all of the sialic acid lost from the cells after activation could be accounted for as free sialic acid recovered in extracellular media, suggesting that some degree of sialate degradation may occur as a consequence of neutrophil activation.

Effects of the sialidase inhibitor, 2-deoxyNANA, on stimulated neutrophil aggregation and adhesion responses As illustrated in Fig. 6, homotypic aggregation responses of neutrophils activated by PMA, IMN, or AMLF, were found to be kinetically similar under each activation condition to the appearance of cell surface sialidase activity and loss of cell-associated sialic acid. Aggregation responses were also found to be inhibited in a dose-responsive fashion by 2-deoxyNANA. In contrast, 2-keto-3-deoxyoctulosonic acid (or KDO), which has electrophysical properties similar to 2-deoxyNANA but does not inhibit sialidase activity, did not interfere with neutrophil 

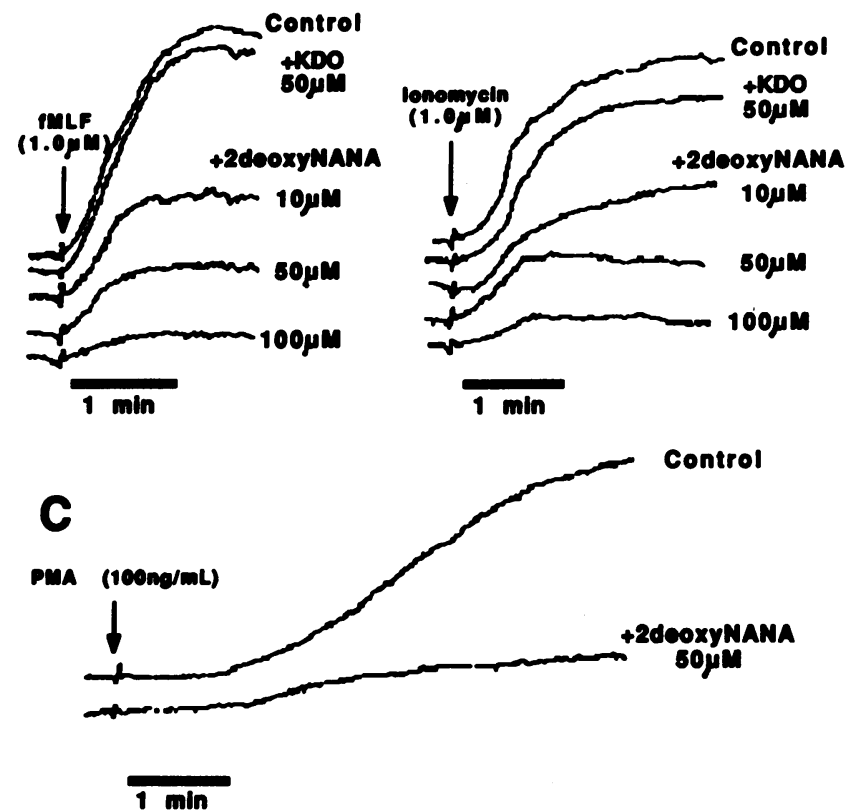

Figure 6. Homotypic aggregation responses of neutrophils activated by $\mathrm{AMLF}(A)$, ionomycin $(B)$, or PMA $(C)$. Neutrophils were incubated in either buffer alone (control) or in buffer to which the specific sialidase inhibitor, 2-deoxyNANA $(10-100 \mu \mathrm{M}$, or 3-30 $\mu \mathrm{g} / \mathrm{ml})$, or KDO had been added. Changes in light transmission over time are shown by chart recorder tracings taken from representative studies.

aggregation at comparable concentrations. Free sialic acid (NANA) was also found to inhibit aggregation responses but was less active in this regard than 2-deoxyNANA (results not shown).

In separate studies, microbial neuraminidase was found to induce a gradual neutrophil aggregation response, illustrated in Fig. $7 \mathrm{~A}$, and this effect of neuraminidase could be blocked completely by 2-deoxyNANA. Furthermore, when the combined effects of neuraminidase and various concentrations of fMLF were examined, it was found that pretreatment of neutrophils with neuraminidase enhanced the aggregation response triggered by a subsequent stimulation with fMLF. This effect was most noticeable with suboptimal stimulatory doses of peptide (Fig. $7 \mathrm{~B}$ ). The addition of neuraminidase $1-2 \mathrm{~min}$ after exposure of neutrophils to these same doses of $\mathrm{MLF}$, on the other hand, did not alter the character of the gradual aggregation response induced by neuraminidase alone (data not shown).

As shown in Table II, 2-deoxyNANA and NANA were also found to inhibit the adhesion of neutrophils, both with and without concomitant stimulation by fMLF $(0.1 \mu \mathrm{M})$, to nylon fiber mini-columns (see Methods) and also to the surfaces of plastic tissue culture wells; inhibition was dose responsive and was observed at the same concentrations as those found to inhibit homotypic neutrophil aggregation. In contrast, $\mathrm{KDO}$ at comparable concentrations had little or no effect on neutrophil adhesion to nylon fibers or plastic. The inhibitory effects of 2-deoxyNANA and NANA, shown in Table II, were most readily detected under experimental conditions with which adhesion was limited or incomplete. These effects became less apparent when conditions were modified to enhance the extent
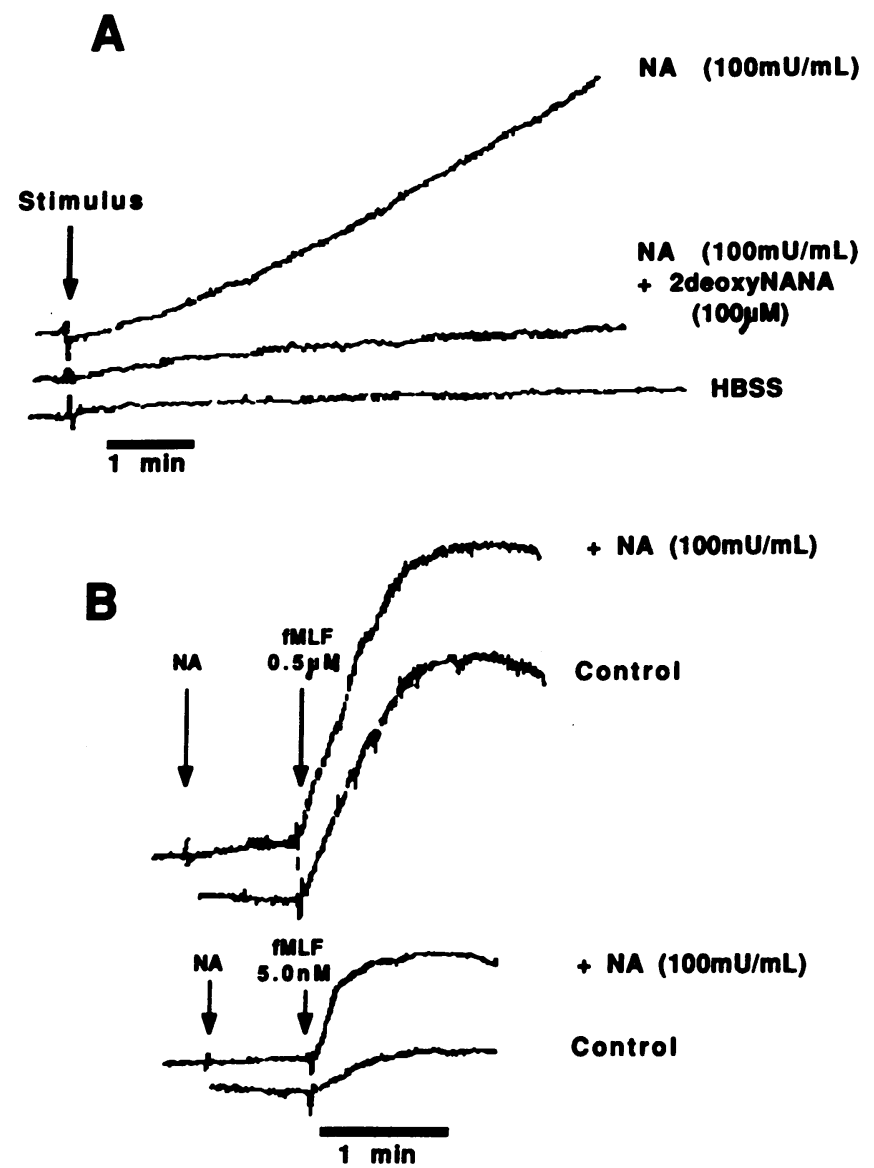

Figure 7. Homotypic aggregation responses of neutrophils incubated with buffer alone or with neuraminidase (NA, $100 \mathrm{mU} / \mathrm{ml}$ ), with or without 2-deoxyNANA, are shown in $A$. Aggregation responses of neutrophils to suboptimal or optimal concentrations of $\mathrm{MLF}$, with or without prior addition of neuraminidase $(N A)$, are shown in $B$. Changes in light transmission over time are shown by chart recorder tracings taken from representative studies.

of adhesion (e.g., increasing cell concentrations $>5 \times 10^{6} / \mathrm{ml}$ and/or nylon fiber packing $>30 \mathrm{mg} /$ column in assays of nylon fiber adhesion, or increasing incubation times to $\geq 5 \mathrm{~min}$ in assays of adherence to plastic culture wells).

\section{Discussion}

Subcellular fractionation studies of human neutrophils, described here, indicate that neutrophil sialidase is stored, like lysozyme, in both primary and secondary neutrophil granules. These studies also show that sialidase activity is detectable in plasma membrane-rich fractions of neutrophils, and that this activity increases substantially after activation of the cells with soluble stimuli, reflecting a translocation of sialidase to the plasma membrane from a subcellular compartment that cosediments with secondary granules. All sialidase activity recovered from granule fractions in general, and from secondary granule fractions in particular, was not equally accessible for mobilization to the plasma membrane. Moreover, translocation of sialidase activity to the plasma membrane was observed under conditions of neutrophil activation (e.g., fMLF stimulation without cytochalasin) with which little or no exocytosis of 
Table II. Adherence of Neutrophils to Nylon Fibers and to Plastic

\begin{tabular}{lrc}
\hline Experimental conditions & $\begin{array}{c}\text { Adherence to } \\
\text { nylon fibers* }\end{array}$ & $\begin{array}{c}\text { Adherence to } \\
\text { plastic culture wells* }\end{array}$ \\
\hline Control & $58.4 \pm 2.6$ & $38.5 \pm 1.7$ \\
+2-deoxyNANA $(7.5 \mu \mathrm{g} / \mathrm{ml})^{\ddagger}$ & $40.3 \pm 5.9$ & $19.2 \pm 1.3$ \\
+2-deoxyNANA $(15 \mu \mathrm{g} / \mathrm{ml})$ & $19.8 \pm 2.5$ & $14.8 \pm 1.5$ \\
+2-deoxyNANA $(30 \mu \mathrm{g} / \mathrm{ml})$ & $9.6 \pm 3.1$ & $10.6 \pm 1.0$ \\
+NANA $(50 \mu \mathrm{g} / \mathrm{ml})$ & $49.4 \pm 1.8$ & $21.6 \pm 0.6$ \\
+NANA $(100 \mu \mathrm{g} / \mathrm{ml})$ & $38.5 \pm 2.9$ & $14.8 \pm 1.0$ \\
+NANA $(250 \mu \mathrm{g} / \mathrm{ml})$ & $31.4 \pm 4.3$ & $12.5 \pm 1.7$ \\
+KDO $(75 \mu \mathrm{g} / \mathrm{ml})$ & $57.4 \pm 2.6$ & $32.2 \pm 1.5$ \\
fMLF $(0.1 \mu \mathrm{M})$ & $81.3 \pm 3.8$ & $59.4 \pm 3.4$ \\
+2-deoxyNANA $(7.5 \mu \mathrm{g} / \mathrm{ml})$ & $56.3 \pm 2.1$ & $42.5 \pm 3.4$ \\
+2-deoxyNANA $(15 \mu \mathrm{g} / \mathrm{ml})$ & $43.8 \pm 6.7$ & $31.3 \pm 6.8$ \\
+2-deoxyNANA $(30 \mu \mathrm{g} / \mathrm{ml})$ & $35.4 \pm 7.1$ & $26.1 \pm 6.8$ \\
+NANA $(50 \mu \mathrm{g} / \mathrm{ml})$ & $67.5 \pm 2.1$ & $45.2 \pm 5.0$ \\
+NANA $(100 \mu \mathrm{g} / \mathrm{ml})$ & $56.3 \pm 2.5$ & $36.4 \pm 4.0$ \\
+NANA $(250 \mu \mathrm{g} / \mathrm{ml})$ & $47.9 \pm 2.5$ & $29.7 \pm 5.0$ \\
+KDO $(75 \mu \mathrm{g} / \mathrm{ml})$ & $79.2 \pm 2.9$ & $64.5 \pm 5.6$ \\
& & \\
\hline
\end{tabular}

* Results, expressed as percent adherence (see Methods), represent mean values \pm SEM for four replicate measurements. ${ }^{\ddagger} 7.5 \mu \mathrm{g} / \mathrm{ml}$ 2-deoxyNANA $=25 \mu \mathrm{M}$.

granule contents was detected. These findings suggest that the sialidase activity translocated to the plasma membrane during neutrophil activation is derived principally from a highly mobilizable subcellular compartment that cosediments with but may be distinct from most secondary granules, as has been described by Borregaard et al. for latent alkaline phosphatase in neutrophils (34). These findings also raise the possibility that the sialidase activity recovered from neutrophils may be derived from multiple enzyme species that occupy distinct functional compartments. Although our studies did not reveal clear differences in the biochemical characteristics of sialidase activities recovered from different subcellular compartments, they did not rule out this possibility; indeed, others have reported that neutrophils contain at least two distinct isoforms of sialidase (16).

Sialidase activity was also found to appear rapidly on the surface of intact neutrophils during activation, coincident with a loss of total cell-associated sialic acid and release of sialic acid into the extracellular medium, and with kinetics that differed depending on the stimulus employed. Interestingly, the appearance of sialidase activity on the surface of intact neutrophils activated by fMLF or ionophore was found to be transient. We suspect that the rapid appearance and disappearance of sialidase activity observed under these activation conditions reflects a short-lived mobilization of sialidase to the cell surface followed by binding to endogenous substrates such that the enzyme rapidly becomes inaccessible for interactions with exogenous substrate (e.g., 4MU-NANA). The finding of a similarly rapid appearance and disappearance of binding activity for exogenous, radiolabelled sialate by ionomycin-activated neutrophils is consistent with this interpretation.

Both activation-induced increases in cell surface sialidase and loss of cell-associated sialic acid could be blocked by incubation of neutrophils with the sialidase inhibitor, 2-deoxyNANA, which was also found to inhibit stimulated neutrophil aggregation and adherence to nylon fibers and plastic surfaces.
Considered together, these findings suggest that desialation of glycosylated molecules on the surface of neutrophils is mediated by an endogenous sialidase which is mobilized during cell activation. Furthermore, these events appear to have a role in stimulated adhesion responses of these cells.

There was no evidence from our studies that a soluble sialidase activity is released by neutrophils. Indeed, this enzymatic activity was recoverable in a soluble form from both resting and activated, intact neutrophils and from subcellular fractions only after detergent treatment. It is possible that sialidase may be released from activated neutrophils, but is rapidly inactivated, perhaps via oxidative modification (35). However, neither intact neutrophils nor neutrophil extracts were found to modify the activity of microbial neuraminidase. Hence, these findings suggest that the activity of sialidase mobilized to the neutrophil surface is largely limited to endogenous substrates or to targets directly adherent to the cells.

Previous studies have established that $\sim 70 \%$ of the sialic acid content of neutrophils is associated with the cell membrane and may be released by treatment of the cells with neuraminidase (36). Previous studies have also suggested that cell surface sialation may be related to certain functional attributes of myeloid cells $(6,7)$. Immature myeloid cells are characterized by a high degree of sialation, a high degree of negative surface charge (which is diminished by neuraminidase treatment), cellular rigidity, and limited adhesiveness. Moreover, immature myeloid cells have been shown to have an increased lifespan in the circulation and a limited capacity to marginate or enter inflammatory exudates. As myeloid cells mature, they acquire increased deformability and adhesiveness, together with decreases in both negative cell surface charge and sialic acid content $(6,7)$. While it is now clear that the synthesis and expression of specific adhesion proteins (e.g., CD11/CD18) on the surface of neutrophils during their maturation in the marrow is critical to their acquisition of adhesive properties (37), cell surface sialation appears to have a role in this and other aspects of neutrophil function.

Abrahamson suggested more than 60 years ago that a decrease in negative surface charge might facilitate the adhesion of neutrophils to endothelial surfaces during the initial stages of an inflammatory response (38). More recently, decreases in the negative surface charge of neutrophils have been shown to occur after exposure of the cells to chemotactic factors and degranulating stimuli, and it was suggested that this change might be a prerequisite for normal cell movement and adhesion responses, given the finding of a correlation between decreased surface charge and both granule exocytosis and cellular adhesiveness (19). Furthermore, incubation of neutrophils with microbial neuraminidase, which is known to reduce neutrophil surface charge (7), has also been found to promote the adhesion of neutrophils to nylon fibers (39) and to endothelial cells (40), mimicking in some respects the stimulatory effects of chemotactic factors on neutrophil adhesiveness.

In our studies, we observed that neuraminidase treatment induced neutrophils to aggregate, but this response was relatively slow to develop compared with the very rapid aggregation responses induced by $\mathrm{MLF}$ or ionomycin. This finding raises the possibility that the endogenous neutrophil sialidase, mobilized to the cell surface during neutrophil activation, may be more efficient than exogenous microbial neuraminidases in mediating functionally important desialation events involved in the induction of aggregation responses, either because of more favorable access to relevant cellular substrates or because 
of differences in substrate specificities. Indeed, differences in substrate specificities among sialidases are well recognized (41), and our studies documented such differences in comparing neutrophil sialidase and $V$. cholerae neuraminidase. In particular, we found that the sialidase present in neutrophil extracts was more active relative to the microbial neuraminidase in releasing free sialic acid from intact neutrophils than it was in releasing sialic acid from other substrates.

Free sialic acid is known to inhibit the activity of sialidases (42), and in our studies sialic acid was found to inhibit neutrophil aggregation and adhesion responses, although it was less potent in this regard than 2-deoxyNANA. This finding is of interest in light of studies reported by Gorog et al. (43) who observed that intravenous infusions of free sialic acid into rabbits caused a decrease in the adherence of granulocytes to endothelial walls of postcapillary venules examined in ear chamber preparations in vivo. These investigators also found that sialic acid infusions induced a granulocytosis in rats that was associated with the release of marginated leukocytes into the circulation (43).

The glycosylated molecules on the surface of neutrophils that are substrates for neutrophil sialidase and may be involved in neutrophil adhesion responses remain to be identified. However, it is possible that either the beta- 2 integrin adhesion molecules, CD11/CD18 $(44,45)$, or the ligands on neutrophils that bind to CD11/CD18 are functionally important targets for desialation associated with neutrophil activation. The recent finding that deglycosylated forms of intercellular adhesion molecule 1 (ICAM-1) (CD54) bind more avidly to CD11b/CD18 (Mac-1) lends credence to this possibility (46), since there is now substantial evidence that ICAM-1, which has been shown to bind lymphocyte function-associated antigen (LFA-1) and to mediate homotypic aggregation of lymphocytes, is a cellular counterreceptor or ligand for CD1 1b/CD18 that is involved in mediating CD18-dependent neutrophil adhesion phenomena including homotypic aggregation $(45,46)$. Although a mobilization of CD11/CD18 adhesion molecules to the cell surface occurs during neutrophil activation, recent studies have shown that an increased density of CD11/CD18 at the cell surface is neither necessary nor sufficient for the increased adhesiveness of activated neutrophils (47). Hence, it has been suggested that a posttranslational modification of the CD11/CD18 molecules, such as an activation-dependent phosphorylation event, may be involved in the expression of the adhesive properties of CD11/CD18 heterodimers (48). Our studies raise the additional possibility that desialation of these glycoprotein complexes, or other glycoproteins that participate in adhesion responses, may promote or reveal the adhesive functions of these cell surface molecules. This possibility is of particular interest in light of the finding that LFA-1 molecules on lymphocytes, which are structurally related to neutrophil CD1 1/CD18 adhesion molecules, express differing degrees of sialylation among functionally distinct lymphocyte subpopulations (49).

Adhesion of neutrophils to platelets and endothelial cells has also been shown recently to be mediated in part by interactions with lectinlike molecules that are exposed on the surface of activated platelets and endothelial cells (50-53). These lectin-like receptors (endothelial-leukocyte adhesion molecules 1) (ELAM-1) on endothelial cells [53], and guanosine 5'-monophosphate-140 (GMP-140) [50, 51], or platelet activation dependent granule-external membrane protein [52] on platelets and endothelial cells are members of a structurally related family of adhesion proteins (lectin cellular adhesion molecules
[LEC-CAMs] or selectins) which include the murine lymphocyte $\mathrm{gp} 90^{\mathrm{mel}-14}(54)$ and are known to mediate cell-cell adhesion by binding to complex cell surface carbohydrates. A lectinlike adhesion protein (gp100 $\left.10{ }^{\mathrm{met}-14}\right)$, structurally related to GMP-140 and ELAM-1, has also been identified on neutrophils, although its role in neutrophil aggregation and adhesion responses has yet to be fully defined (55). Recently, the ligand for ELAM-1 has been identified as sialyl-Lewis X, a terminal carbohydrate structure found on cell-surface glycoproteins and glycolipids of neutrophils $(56,57)$. Studies using specific monoclonal antibodies that recognize either the sialated or asialo forms of this carbohydrate structure have indicated that the sialic acid residue may be required for efficient binding to ELAM-1 and related lectin adhesion molecules (56). Hence, we infer from these studies that the enhancement of neutrophil adhesion phenomena associated with neutrophil desialation, observed in our studies, does not involve the ELAM-1 ligand, since desialation of sialyl-Lewis $\mathrm{X}$ molecules on neutrophils might be anticipated to reduce (not promote) intercellular adhesion events dependent upon these structures. Nonetheless, desialation of the ELAM-1 ligand by an endogenous sialidase mobilized to the surface of activated neutrophils could modulate adhesion events mediated by the selectin family of adhesion molecules following the binding of neutrophils to endothelial cells and during transendothelial migration of neutrophils in response to inflammatory signals.

Desialation of glycosylated molecules on the surface of neutrophils may affect functions other than those related to stimulated adhesion. Indeed, neuraminidase treatment of neutrophils has been reported to modify stimulated superoxide and hydrogen peroxide generation by these cells, although reports of such effects have been conflicting $(9,58-61)$. Recently Perez et al. have reported that neuraminidase treatment inhibits chemotactic responses of neutrophils, and they have related this effect to an inhibition of the recycling of chemotactic factor receptors (62). Our studies support the conclusion that efforts to identify functionally important desialation targets on the surface of neutrophils should contribute to a more complete understanding of molecular mechanisms involved in the induction of neutrophil functional responses by inflammatory signals, for it is evident that desialation of the neutrophil surface, mediated by an endogenous sialidase, is a component of neutrophil activation.

\section{Acknowledgments}

The authors wish to thank Lynnette Young for her superb technical assistance.

\section{References}

1. Corfield, A. P., and R. Schauer. 1982. Occurrence of sialic acids. In Sialic Acids: Chemistry, Metabolism and Function. Cell Biology Monographs. Vol. 10. R. Schauer, editor. Springer-Verlag, Vienna, New York. 5-50.

2. Dennis, J., C. Waller, R. Timpl, and V. Schirrmacher. 1982. Surface sialic acid reduces attachment of metastatic tumor cells to collagen type IV and fibronectin. Nature (Lond.) 300:274-276.

3. Fogel, M., P. Altevogt, and V. Schirrmacher. 1983. Metastatic potential severely altered by changes in tumor cell adhesiveness and cell surface sialylation. J. Exp. Med. 157:371-376.

4. Pearlstein, E., P. L. Salk, G. Yogeeswaran, and S. Karpatkin. 1980. Correlation between spontaneous metastatic potential, platelet-aggregating activity of cell surface extracts, and cell surface sialylation in 10 metastatic-variant derivatives of a rat renal sarcoma cell line. Proc. Natl. Acad. Sci. USA. 77:4336-4339.

5. Lloyd, C. W. 1975. Sialic acid and the social behavior of cells. Biol. Rev. 50:325-350.

6. Lichtman, M. A., and R. I. Weed. 1972. Alteration of the cell periphery during granulocyte maturation: relationship to cell function. Blood. 39:301-316. 
7. Lichtman, M. A., and R. I. Weed. 1970. Electrophoretic mobility and $\mathrm{N}$-acetyl neuraminic acid content of human normal and leukemic lymphocytes and granulocytes. Blood. 35:12-22.

8. Weiss, L. 1965. Studies on cell deformability. I. Effect of surface charge. J. Cell Biol. 26:735-739.

9. Henricks, P. A. J., M. E. Van Erne-van der Tol, and J. Verhoef. 1982 Partial removal of sialic acid enhances phagocytosis and the generation of superoxide and chemiluminescence by polymorphonuclear leukocytes. J. Immunol. 129:745-750.

10. Corfield, A. P., and R. Schauer. 1982. Metabolism of sialic acids. In Sialic Acids: Chemistry, Metabolism, and Function. Cell Biology Monographs. Vol. 10. R. Schauer, editor. Springer-Verlag, Vienna, NY. 195-261.

11. Michalski, J.-C., A. P. Corfield, and R. Schauer. 1986. Properties of human liver lysosomal sialidase. Biol. Chem. Hoppe-Seyler. 367:715-722.

12. Samollow, P. A., J. L. VandeBerg, H. W. Kunz, and T. J. Gill III. 1985 Analysis of neuraminidase isozyme phenotypes in mammalian tissues: an electrophoretic approach. Biochem. Biophys. Res. Commun. 126:1182-1188.

13. Miyagi, T., and S. Tsuiki. 1985. Purification and characterization of cytosolic sialidase from rat liver. J. Biol. Chem. 260:6710-6716.

14. Schauer, R. 1985. Sialic acids and their role as biological masks. Trends Biochem. Sci. 10:357-360.

15. Nojiri, H., F. Takaku, T. Tetsuka, and M. Saito. 1982. Stimulation of sialidase activity during cell differentiation of human promyelocytic leukemia cell line HL-60. Biochem. Biophys. Res. Commun. 104:1239-1246.

16. Verheijen, F. W., H. C. Janse, O. P. van Diggelen, H. D. Bakker, M. C. B. Loonen, P. Durand, and H. Galjaard. 1983. Two genetically different MUNANA neuraminidases in human leucocytes. Biochem. Biophys. Res. Commun. 117:470-478.

17. Gallin, J. I., D. G. Wright, and E. Schiffmann. 1978. Role of secretory events in modulating human neutrophil chemotaxis. J. Clin. Invest. 62:1364 1374.

18. Gallin, J. I., J. R.Durocher, and A. P. Kaplan. 1975. Interaction of leukocyte chemotactic factors with the cell surface. I. Chemotactic factor-induced changes in human granulocyte surface charge. J. Clin. Invest. 55:967-974.

19. Gallin, J. I. 1980. Degranulating stimuli decrease the negative surface charge and increase the adhesiveness of human neutrophils. J. Clin. Invest. 65:298-306.

20. Cross, A. S., G. H. Lowell, J. Palmblad, J. C. Sadoff, L. Young, and M. Berger. 1985. Mechanism of priming of human neutrophils by a soluble lymphoblastoid cell factor. J. Immunol. 135:2074-2083.

21. Wright, D. G. 1988. Neutrophil degranulation. Methods Enzymol. 162:538-551.

22. Wright, D. G., and J. I. Gallin. 1979. Secretory responses of human neutrophils. J. Immunol 123:285-294.

23. Borregaard, N., J. M. Heiple, E. R. Simons, and R. A. Clark. 1983. Subcellular localization of the b-cytochrome component of the human microbicida oxidase: translocation during activation. J. Cell Biol. 97:52-61.

24. Wright, D. G., D. Bralove, and J. I. Gallin. 1977. The differential mobilization of human neutrophil granules. Am. J. Pathol. 87:272-284.

25. Baggiolini, M., J. G. Hirsch, and C. DeDuve. 1969. Resolution of granules from rabbit heterophil leukocytes into distinct populations by zonal sedimentation. J. Cell Biol. 40:529-541.

26. Kane, S. P., and T. J. Peters. 1975. Analytical subcellular fractionation of human granulocytes with reference to the localization of vitamin $B_{12}$ binding protein. Clin. Sci. Mol. Med. 49:171-182.

27. DeChatelet, L. R., and M. R. Cooper. 1970. A modified procedure for the determination of leukocyte alkaline phosphatase. Biochem. Med 4:61-68.

28. Pereira, M. E. A. 1983. A rapid and sensitive assay for neuraminidase using peanut lectin hemagglutination: application to Vibrio cholera and Trypano soma cruzi. J. Immunol. Meth. 63:25-34.

29. Warren, L. 1959. The thiobarbituric acid assay of sialic acids. J. Biol. Chem. 234:1971-1975.

30. Brunetti, P., A. Swanson, and S. Roseman. 1963. Enzymatic determination of sialic acids. In Methods in Enzymology. VI. Academic Press, New York London. pp. 465-473.

31. Metcalf, J. A., J. I. Gallin, W. M. Nauseef, and R. K. Root. Laboratory Manual of Neutrophil Function. 1986. Raven Press, Ltd., NY.

32. Spaltro, J., and J. A. Alhadeff. 1984. Solubilization, stabilization and isoelectric focusing of human liver neuraminidase activity. Biochim. Biophys. Acta. 800:159-165.

33. Kumar, V., J. Kessler, M. E. Scott, B. H. Patwardhan, S. W. Tanenbaum, and M. Flashner. 1981. 2,3-dehydro-4-epi- $N$-acetylneurminic acid; a neuraminidase inhibitor. Carbohydr. Res. 94:123-130.

34. Borregaard, N., L. Christensen, O. W. Bejerrum, H. S. Birgens, and I. Clemmensen. 1990. Identification of a highly mobilizable subset of human neutrophil intracellular vesicles that contain tetranectin and latent alkaline phosphatase. J. Clin. Invest. 85:408-416.

35. Clark, R. A., and N. Borregaard. 1985. Neutrophils autoinactivate secretory products by myeloperoxidase-catalyzed oxidation. Blood. 65:375-381.

36. DePierre, J. W., J. Lazdins, and M. L. Karnovsky. 1980. The determination and localization of sialic acid in guinea-pig granulocytes. Biochem. J. 192:543-550.
37. Anderson, D. C., F. C. Schmalsteig, M. J. Finegold, B. J. Hughes, R. Rothlein, L. J. Miller, S. Kohl, M. F. Tosi, R. L. Jacobs, T. C. Waldrop, et al 1985. The severe and moderate phenotypes of heritable Mac-1, LFA-1 deficiency: their quantitative definition and relation to leukocyte dysfunction and clinical features. J. Infect. Dis. 152:668-689.

38. Abrahamson, H. A. 1927. The mechanism of the inflammatory process. I. The electrophoresis of the blood cells of the horse and its relation to leukocyte emigration. J. Exp. Med. 46:987-1002.

39. Kownatzki, E., S. Uhrich, and B. Weil. 1984. Adherence and migration of guinea pig granulocytes after enzyme treatment of the cell surface. Immunobiology. 166:111-117.

40. Hoover, R. L., R. T. Briggs, and M. J. Karnovsky. 1978. The adhesive interaction between polymorphonuclear leukocytes and endothelial cells in vitro. Cell. 14:423-428.

41. Michalski, J. C., A. P. Corfield, and R. Schauer. 1982. Properties of human liver lysosomal sialidase. Hoppe-Seyler's Z. Physiol. Chem. 363:1097-1 102.

42. Mendla, K., and M. Cantz. 1984. Specificity studies on the oligosaccharide neuraminidase of human fibroblasts. Biochem. $J$. 218:625-628.

43. Gorog, P., I. B. Kovacs, and G. V. R. Born. 1980. Suppression of the intravascular adherence of granulocytes by $\mathrm{N}$-acetyl neuraminic (sialic) acid. $\mathrm{Br}$. J. Exp. Pathol. 61:490-496.

44. Sanchez-Madrid, F., J. Nagy, E. Robbins, P. Simon, and T. A. Springer 1983. A human leukocyte differentiation antigen family with distinct alpha sub units and a common beta subunit: the lymphocyte function associated antigen-1 (LFA-1), the C3bi complement receptor (OKM1/Mac-1), and the p150.95 molecule. J. Exp. Med. 158:1785-1803.

45. Carlos, T. M., and J. M. Harlan. 1990. Membrane proteins involved in phagocyte adherence to endothelium. Immunol. Rev. 114:5-28.

46. Diamond, M. S., D. E. Staunton, S. D. Marlin, and T. A. Springer. 1991. Binding of the integrin Mac-1 (CD1 1b/CD18) to the third immunoglobulin-like domain of ICAM-1 (CD54) and its regulation by glycosylation. Cell. 65:961-971.

47. Vedder, N. B., and J. M. Harlan. 1988. Increased surface expression of $\mathrm{CD} 1 \mathrm{~b} / \mathrm{CD} 18$ (Mac-1) is not required for stimulated neutrophil adherence to cultured endothelium. J. Clin. Invest. 81:676-682.

48. Buyon, J. P., S. G. Slade, J. Reibman, S. B. Abramson, M. Philips, G Weissmann, and R. Winchester. 1990. Constitutive and induced phosphorylation of the $\alpha$-and $\beta$-chains of the CD11/CD18 leukocyte integrin family: relationship to adhesion-dependent functions. J. Immunol. 144:191-197.

49. Takeda, A. 1987. Sialylation patterns of lymphocyte function-associated antigen 1 (LFA-1) differ between $\mathrm{T}$ and B lymphocytes. Eur. J. Immunol 17:281-286.

50. McEver, R. P., J. H. Beckstead, K. L. Moore, L. Marshall-Carlson, and D. F. Bainton. 1989. GMP-140, a platelet alpha-granule membrane protein, is also synthesized by vascular endothelial cells and is localized in Weibel-Palade bodies. J. Clin. Invest. 84:92-99.

51. Johnston, G., R. G. Cook, and R. P. McEver. 1989. Cloning of GMP-140, a granule membrane protein of platelets and endothelium: sequence similarity to proteins involved in cell adhesion and inflammation. Cell. 56:1033-1044.

52. Larsen, E., A. Celi, G. E. Gilbert, B. C. Furie, J. K. Erban, R. Bonfanti, D. D. Wagner, and B. Furie. 1989. PADGEM protein: a receptor that mediates the interaction of activated platelets with neutrophils and monocytes. Cell. 59:305-312.

53. Bevilacqua, M. P., J. S. Pober, D. L. Mendrick, R. S. Cotran, and M. A. Gimbrone, Jr. 1987. Identification of an inducible endothelial-leukocyte adhesion molecule, ELAM-1. Proc. Natl. Acad. Sci. USA. 84:9238-9242.

54. Lewinsohn, D. M., R. F. Bargatze, and E. C. Butcher. 1987. Leukocyte-endothelial cell recognition: evidence of a common molecular mechanism shared by neutrophils, lymphocytes, and other leukocytes. J. Immunol. 138:4313-4321.

55. Kishimoto, T. K., M. A. Jutila, E. L. Berg, and E. C. Butcher. 1989. Neutrophil Mac-1 and MEL-14 adhesion proteins inversely regulated by chemotactic factors. Science (Wash. DC). 245:1238-1241.

56. Phillips, M. L., E. Nudelman, F. C. A. Gaeta, M. Perez, A. K. Singhal, S.-I. Hakomori, and J. C. Paulson. 1990. ELAM-1 mediates cell adhesion by recognition of a carbohydrate ligand, sialyl-Le ${ }^{\times}$. Science (Wash. DC) 250:1130-1132.

57. Walz, G., A. Aruffo, W. Kolanus, M. Bevilacqua, and B. Seed. 1990. Recognition by ELAM-1 of the sialyl-Le $e^{x}$ determinant on myeloid and tumor cells. Science (Wash. DC). 250:1132-1135.

58. Tsan, M. F., and P. A. McIntyre. 1976. The requirement for membrane sialic acid in the stimulation of superoxide production during phagocytosis by human polymorphonuclear leukocytes. J. Immunol. 129:745-750.

59. Suzuki, H., T. Kurita, and K. Kakinuma. 1982. Effects of neuraminidase on $\mathrm{O}_{2}^{-}$consumption and release of $\mathrm{O}_{2}^{-}$and $\mathrm{H}_{2} \mathrm{O}_{2}$ from phagocytosing human polymorphonuclear leukocytes. Blood. 60:446-453.

60. Noseworthy, J., H. Korchak, and M. L. Karnovsky. 1972. Phagocytosis and the sialic acid of the surface of polymorphonuclear leukocytes. J. Cell. Physiol. 79:91-96.

61. Perez, H D. R R Ong and F. Elfman 1985. Removal or oxidation of surface membrane sialic acid inhibits formyl-peptide-induced polymorphonuclear leukocyte chemotaxis. J. Immunol. 134:1902-1908.

62. Perez, H. D., F. Elfman, and E. Lobo. 1987. Removal of human polymorphonuclear leukocyte surface sialic acid inhibits reexpression (or recycling) of formyl peptide receptors. J. Immunol. 139:1978-1984. 